\title{
Influence of Surface Roughening of the Raw Material on the Lap Shearing Strength and Failure Behavior of Adhesively Bonded Aluminum Joints
}

Jianpeng Liu

Hunan University

\section{Wei Wang}

Geely Automobile Research Institute (Ningbo) Co.

\section{Yong Yan}

China North Advanced Technology Generalization Institute

Hong He ( $\nabla$ hehong_hnu@hnu.edu.cn )

Hunan University

\section{Zhigang Xue}

Hunan University

\section{Congchang $\mathrm{Xu}$}

Hunan University

\section{Luoxing Li}

Hunan University

\section{Research Article}

Keywords: Surface treatments, Wettability, Bonded joints, Failure behavior, Interfacial adhesion, Lap shearing strength

Posted Date: January 28th, 2022

DOI: https://doi.org/10.21203/rs.3.rs-1244699/v1

License: (a) (1) This work is licensed under a Creative Commons Attribution 4.0 International License. Read Full License 


\section{Influence of surface roughening of the raw material on the lap shearing strength and failure behavior of adhesively bonded aluminum joints} Jianpeng Liu ${ }^{1} \cdot$ Wei Wang $^{2} \cdot$ Yong Yan ${ }^{3} \cdot$ Hong He $^{1} \cdot$ Zhigang Xue $^{1} \cdot$ Congchang $\mathrm{Xu}^{1} \cdot$ Luoxing $\mathrm{Li}^{1}$

\section{Abstract}

Surface roughening of the substrates before bonding plays a significant effect on improving the mechanical performance of the adhesively bonded joints, which are prevalently used for light-weighting vehicle bodies. In this study, the influence of surface roughening on the lap shearing strength and failure behavior of adhesively bonded aluminum sheet joints was investigated. Sandpaper grinding was employed for surface roughening, methods such as tensile testing microstructure observation, etc., was employed for evaluating the performance of the joints. The results showed that the lap shearing strength of adhesively bonded joints increased and then decreased with the surface roughness of the aluminum substrate. The maximum shearing strength of the joint bonded with grinded substrates was $30.4 \mathrm{MPa}$ which was improved by $57.5 \%$ compared to that produced with un-grinded substrates. However, over roughening is harmful. When the surface roughness was too large, the failure mode of the joint turned from the mixed failure mode to interfacial failure mode, which decreased the strength of the joints. Related mechanisms were demonstrated. When the substrate surface was

Corresponding author: Hong He; E-mail: hehong hnu@hnu.edu.cn

1. State Key Laboratory of Advanced Design and Manufacturing for Vehicle Body, College of Mechanical and Vehicle Engineering, Hunan University, Changsha 410082, Hunan, China

2. Zhejiang Key Laboratory of Automobile Safety Technology, Geely Automobile Research Institute (Ningbo) Co., Ltd., Ningbo, Zhejiang 315336, PR China.

3. China North Advanced Technology Generalization Institute, Beijing 100089, China 
1 coarsened, the bonding area and the wettability of the adhesive on the surface were both

2 increased, which promoted the beneficial mechanical interlock effect between the

3 adhesive and the substrate. However, when the substrate surface was over roughened,

4 defects such as voids, insufficient infiltrating of the adhesive, etc., were induced, which

5 apparently increased the proportion of the interfacial failure area.

6 Keywords: Surface treatments; Wettability; Bonded joints; Failure behavior;

7 Interfacial adhesion; Lap shearing strength

\section{$8 \quad 1$ Introduction}

Adhesively bonded aluminum structural parts got potential applications in recent years in the design of advanced transportation tools, such as automotive, aircraft and marine applications. Their exceptional performances include light-weighting, sealing, sound insulating, high stiffness and corrosion resistance, etc. Compared to welding, riveting and bolting, the residual stress and micro-cracks in the adhesively bonded joints are much less. The operability and efficiency of the adhesive bonding technology are much higher. For example, it can be operated in a narrow space without sophisticated equipment and can be fully cured along with the paint baking process which is very cost-effective. Therefore, the performances of such bonded and multilayered joints have attracted great attention [1-5].

The mechanical strength and failure behavior under diverse service conditions are the most concerning issues for the adhesively bonded aluminum joints, especially when they are used in vehicle bodies. The dangerous points should be known when engineers design and verify the safety of the structure. They are mainly depended on the cured 
1 adhesive strength, and the bonding interface quality in application which are sensitively

2 influenced by the processing parameters. Many factors are involved, such as the surface

3 state of the adherend, the thickness of the adhesion layer, etc. Among them, the surface

4 roughness of the aluminum substrate to be bonded is the most important. In the early

5 studies as reported in the literature, researchers found the shear strength of the

6 adhesively bonded joints increased with the surface roughness of the metal sheet.

7 Shahid et al. tested the strength of cleavage joints metal sheets with various surface

8 roughness, and found that the cleavage joint strength has a monotonic relationship with

9 the surface roughness of the raw materials []ㅡ. However, the results were examined in a small surface roughness range. Generally, engineers usually prefer to design single lap

11 joints during manufacturing of automobiles and it is essential to know the lap shearing strength of adhesively bonded joints in the scope of a larger surface roughness. Several reports pointed out that there exists a most suitable surface roughness for the raw materials which bring about maximum tensile strength of the adhesively bonded aluminum joints [-10]. Tezcan studied the influence of surface roughness on the adhesively bonded joints strength under impact loading with different strain rates. It was demonstrated that the lap shearing strength of the adhesively bonded joints will be a minimum value when the surface roughness $R_{a}$ of the substrate was less than $0.1 \mu \mathrm{m}$ or higher than $2.5 \mu \mathrm{m}$ [11]. Ghumatkar et al. treated the surface of adherend materials with the different mesh numbers of sandpaper to obtain different parameters of roughness, and found that the maximum strength of aluminum/steel adhesive joints corresponds to the most appropriate surface roughness values. When the surface roughness $R_{a}$ of the 
1 aluminum substrate and the steel substrate were $2.05 \mu \mathrm{m}$ and $1.98 \mu \mathrm{m}$. The maximum

2 strength of the adhesively bonded joints was $4.97 \mathrm{MPa}$ and $6.78 \mathrm{MPa}$ [12]. These

3 studies help engineers to realize that the relevance between the lap shearing strength of

4 the adhesively bonded joints and the surface roughness of the raw materials is not

5 linear. Nevertheless, the related mechanism of this phenomenon is still indistinct.

6 Since surface roughening of the substrate to some extent plays an active effect in

7 strengthening the mechanical behaviors of the adhesively bonded joints, researches

8 were further conducted to study the influence of the surface morphology. A quantity of

9 surface treatment methods was attempted to obtain different surface status, including sandpaper grinding, plasma etching, sandblasting, chemical etching, anodizing, etc.

11 Through these, different types of grooves were obtained, which were found to be 12 effective in reducing stress concentration and improving the adhesion quality by 13 preventing entrapped air at the interface. Using sandpapers with different mesh numbers, Ghumatkar et al found that the surface roughness for aluminum substrates could be achieved in a wide range by the various grinding direction and duration [12].

Da Silva et al verified the influence of grooves and scratches on the joint strength with

17 brittle adhesives and ductile adhesives comparatively. The results showed that scratches or grooves produced by grinded aluminum substrate were harmless and even increase

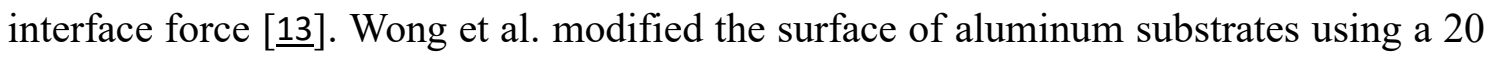
$\mathrm{Hz} \mathrm{Nd}-\mathrm{YAG}$ pulsed laser and generated an aperiodic concentration ring with constant depth and diameter [14]. The results demonstrated that the bonding quality of the adhesive joints was promoted apparently. Among the above methods, mechanical 
1 technology, sandpaper grinding, for example, is still considered to be optimal for large-

2 scale industrial production, in view of the operability, efficiency, and economic cost.

3 Clarifying the mechanisms for the strengthening of the interface of the bonded

4 metal joints through surface treatment of the raw material is crucial for the processing

5 parameters designing. In the study carried out by Ghumatkar et al, they hold the opinion

6 that the improved adhesion quality resulted from mechanical interlocking between the

7 adhesive layer and metal surface [12]. Dong-Jun Kwon et al. investigated the influence

8 of the surface roughness on the interfacial adhesion strength of joints. Experimental

9 results showed that the mechanical anchoring effect of the joints was enhanced by 10 increasing the roughness of the aluminum surface [15]. J.P.B. van Dam et al. 11 investigated the influence of surface roughness on the interfacial adhesion of epoxy 12 adhesively bonded steel joints through different surface treatments. They revealed that 13 surface roughening has a significant impact on the strength in the joints tensile test and 14 the improved shear strength mainly resulted from the increased interfacial bond area 15 [16]. Even though, regarding the mechanisms, the consensus has not been reached. The reason is the adhesive layer itself and the bonding surface are always the weakest part.

17 Furthermore, the dangerous points largely affect the strength of adhesive joints, for example the adhesive layer, the adhesive interface and a mixed mode. The above studies showed results of the increase in strength of adhesively bonded joints by surface roughening, but they did not point out the failure behavior and the strengthening mechanisms. 

modes under tensile or shear load conditions. Pietro Maressa et al. studied failure mechanisms of the adhesively bonded Ti6Al4V sheets with laser processed patterns on

4 the surface, and discovered partial cohesive failure, fully cohesive failure and textured

5 substrates failure in various laser treatments [17]. Chen et al. investigated the damage

6 characteristics and failure behavior of hybrid materials joints, and reported that the

7 adhesive joints showed a combined mode of fiber-tear failure, adhesive failure and

8 cohesive failure [18]. The failure of the bonding surface can be prevented by roughening

9 the substrate surface. Surface chemical modification has also been proved to be an available way to improve the bonding strength because the bonding state during the adhesively bonded joint preparation process is involved. Surface roughening provides the beneficial mechanical interlocking between the aluminum substrate and adhesive, but over roughening would reduce the wettability of the substrates thus the strength of the joints was weakened. Voids possibly occur at the bonding interface in this condition, which accelerates the crack propagation and lowers the strength of the interfacial force. [19-21]For example, the influence of surface characteristics on the strength of adhesively

17 bonded aluminum joints was investigated by Boutar, and found that the bonding quality

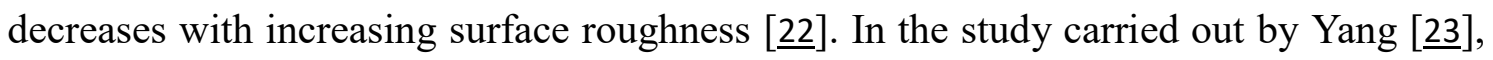
it found that non-permeable zones, an alternation of solid-liquid-gas interfaces were produced if the substrate was over roughened which were both harmful to the bonding quality. 

mechanical strength and failure behavior should be taken into consideration together when engineers evaluate the performance of an adhesively bonded joint. Unfortunately, such comprehensive researches are still few. It triggers our present study. Different

5 surface roughness was produced on the bonding surface of aluminum sheets by grinding 6 with sandpapers of different mesh number. The surface roughness, morphology and free 7 energy, wettability of the adhesive on the aluminum substrates with or without

8 roughening, lap shearing strength and interface failure models of the adhesively bonded 9 joints under shear loading were measured and compared. The contact angle test equipment was used to investigate the relationship between the surface roughness and surface free energy. The influence of surface roughness, microcosmic area and surface free energy on the lap shearing strength was examined. The related mechanisms for the failure behavior of adhesively bonded joints were systematically discussed.

\section{Materials and methods}

\subsection{Raw materials}

A commercial 6063 aluminum alloy in the state of the extruded sheet was used as

17 the raw material, which has excellent mechanical performance and is widely used in the field of automobile manufacturing. Specimens with sizes of $100 \mathrm{~mm}$ in length, $3.8 \mathrm{~mm}$ in thickness and $25 \mathrm{~mm}$ in width were cut by a wire-cut electric discharge machine for adhesive bonding. A structural adhesive for the automobile industry, Dow BETAMATE 1840C, a single component, heat-cured epoxy was employed to the adhesion. Its density 
1 is $1.24 \mathrm{~g} / \mathrm{ml}$ at $23{ }^{\circ} \mathrm{C}$, and the viscosity is $46 \mathrm{~Pa} . \mathrm{S}$ at $45^{\circ} \mathrm{C}$. Its tensile strength is 37.1

$2 \mathrm{MPa}$.

3

4

5

7

\subsection{Surface treatment of the aluminum substrates}

Sandpaper grinding was adopted as the surface treatment of the aluminum sheets, which were subdivided into six groups to investigate the mechanical behaviors of the adhesively bonded joints for tensile testing, as showed in Table 1. Sandpaper mesh numbers of P80, P180, P320, P600, and P800 were used. The sheets were grinded in a single direction that vertical to the tensile load direction of the adhesive joints for tensile testing, as showed in Fig. 1. The grinding time for each sheet was 10 minutes. In Table 1,Sixteen sheets were prepared for each group, and six sheets were used for the test microcosmic surface area, surface free energy and surface roughness respectively, and the remaining ten sheets were bonded into five single lap joints. The surface characteristics were measured at ambient humidity of $42 \pm 3 \%$ and room temperature of $25 \pm 1{ }^{\circ} \mathrm{C}$.

Table 1 The surface treatment of the raw material samples for adhesive bonding

\begin{tabular}{lcccccc}
\hline No & S-0 & A-1 & A-2 & A-3 & A-4 & A-5 \\
\hline Sandpaper size & Un-grinded & P80 & P180 & P320 & P600 & P800 \\
\hline
\end{tabular}

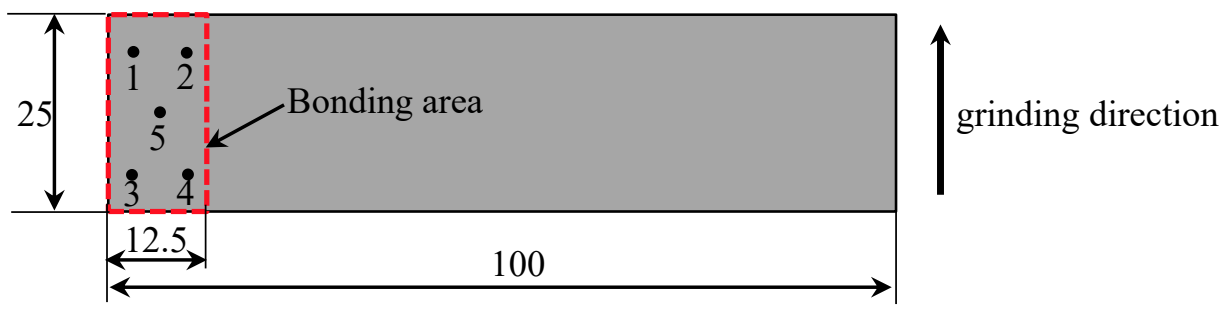

Fig. 1. The sample size and its measurement points (unit: $\mathrm{mm}$ )

\subsection{Surface characterization}


Two roughness parameters for the substrate are $R_{a}$ and $R_{z} . R_{a}$ represents the arithmetic mean of the absolute values of the longitudinal coordinates of the roughness profiles, and $R_{z}$ represents the arithmetic mean value of the individual roughness depth

4 of successive sampling lengths [르]. $R_{z}$ was applied to assessment the surface roughness

5 of the samples throughout this study. Surface roughness values, $R_{a}$ and $R_{z}$ were 6 measured parallel to the load direction using a profilometer (MarSurf PS 10, Germany).

7 For each sample, 5 points as shown in Fig. 1 were selected for testing, and each point 8 was tested for three times. Three specimens of each parameter group as shown in Table

91 were measured, and the average value was regarded as the ultimate result. The surface morphology characteristics and micro surface area of samples were obtained using a VHX-2000C testing machine. surface of the adhesively bonded joints was recorded and the failure area was measured using a DXT-45 single-cylinder stereomicroscope. The percentage of interfacial failure is equal to the proportion of interfacial failure area to the whole overlap area in the adhesively bonded joints.

\subsection{Contact angle testing and surface free energy calculating}

Ordinarily, the considerable level of wettability of aluminum substrate surface is a precondition for good adhesion. It is generally determined by the surface free energy of the substrates to be bonded. The contact angle measurement methods were adopted to compare the change of surface free energy of the aluminum sheets after grinding. The contact angles of testing liquids were performed on a JC-2000D4F analyzer. The 
1 measured values were employed to estimate the surface free energy which was very

2 strongly associated with wettability. The picture of the droplet was captured by a digital

3 camera located in a contact angle measurement instrument, and the images were

4 analyzed using the JC2000DB software. the surface free energies were counted by the

5 Owens-Wendt equation, as shown by Eq. (1). Distilled water and diiodomethane, typical

6 polar and liquid and nonpolar liquid were used, which were selected for contact angles

7 measurement. In the test process, three points were tested on each specimen, and their

8 average values were used as the ultimate results. The test liquid drop volume was 3.36

$9 \mu$ l. Surface tension measurement of liquid at room temperature and its component are shown in Table 2. Taking the surface tension of the liquid-solid-gas triangular points

11 into account in equilibrium equation (Eq. (2)), the surface free energy $\gamma_{s}$ with its dispersive component $\gamma_{s}^{d}$ and polar component $\gamma_{s}^{p}$ of the substrates were counted [드] as

13 below:

$$
\mathrm{W}_{a}=\gamma_{\mathrm{L}}(1+\cos \theta)=2 \sqrt{\gamma_{\mathrm{S}}^{d} \gamma_{L}^{d}}+2 \sqrt{\gamma_{S}^{p} \gamma_{L}^{p}}
$$

$$
\gamma_{\mathrm{s}}=\gamma_{s}^{p}+\gamma_{s}^{d}
$$

where $\theta$ represents the contact angle, and $W_{a}$ represents the work of adhesion, the total surface energy, $\gamma_{s}$ represents the sum of the polar component $\gamma_{s}^{p}$ and dispersive component $\gamma_{s}^{d}$.

For the liquid-solid interaction system through dispersion forces, Eq. (2) can be derived by considering the geometrical average of two liquid dispersion component, and Eq. (3) can be introduced:

$$
\gamma_{s l}=\gamma_{s}+\gamma_{L}-2\left(\gamma_{s}^{d} \gamma_{L}^{s}\right)^{1 / 2}
$$

or Eq. (4): 


$$
\gamma_{L}(1+\cos \theta)=2\left(\gamma_{s}^{d} \gamma_{L}^{s}\right)^{1 / 2}
$$

While the diiodomethane and the water contact angles on the samples were tested at the room temperature, the components $\gamma_{s}^{p}$ and $\gamma_{s}^{d}$ of the aluminum substrates can be counted according to the Owen-Wendt equations Eqs. (5) and (6):

$$
\begin{gathered}
\left(\gamma_{S}^{d}\right)^{0.5}=\frac{\gamma_{w} \sqrt{\gamma_{d}^{p}}\left(1+\cos \theta_{w}\right)-\gamma_{d} \sqrt{\gamma_{d}^{p}}\left(1+\cos \theta_{d}\right)}{2\left(\sqrt{\gamma_{w}^{d} \gamma_{d}^{p}}-\sqrt{\gamma_{d}^{d} \gamma_{w}^{p}}\right)} \\
\left(\gamma_{S}^{p}\right)^{0.5}=\frac{\gamma_{w}\left(1+\cos \theta_{w}\right)-2 \sqrt{\gamma_{s}^{d} \gamma_{w}^{d}}}{2 \sqrt{\gamma_{w}^{p}}}
\end{gathered}
$$

where: $\gamma_{s}^{d}$ and $\gamma_{s}^{p}$ represent the dispersive component and polar component of the surface free energy of the tested samples, respectively; $\gamma_{d}$ and $\gamma_{w}$ represent the surface free energy of the diiodomethane and water, respectively; $\gamma_{w}^{d}$ and $\gamma_{w}^{p}$ represent the dispersive component and polar component of the surface free energy of water, respectively; $\gamma_{d}^{p}$ and $\gamma_{d}^{d}$ represent the polar component and dispersive component of the surface free energy of diiodomethane, respectively; $\theta_{\mathrm{w}}$ and $\theta_{d}$ represent the contact angle of water and diiodomethane, respectively. According to Eq. (2), the surface free energy of joints with different surface treatments can be calculated.

Table 2 The components and its surface free energy of the measured liquids at room temperature, in $\mathrm{mN} / \mathrm{m}$.

\begin{tabular}{lccc}
\hline Testing liquids & $\gamma_{L}$ & $\gamma_{L}^{p}$ & $\gamma_{L}^{d}$ \\
\hline Diiodomethane & 50.8 & 0 & 50.8 \\
Distilled water & 72.8 & 51.0 & 21.8 \\
\hline
\end{tabular}

In order to completely comprehend the wetting status of the adhesive on the aluminum surface and to validate the test results for the test liquids, the contact angles of the $1840 \mathrm{C}$ structural adhesive on the aluminum substrates surface at $180^{\circ} \mathrm{C}$, which was beyond its melting point, were also tested for comparison. The same testing and 
1 calculating methods as described above were adopted. The only difference was that the

2 testing platform was constantly heated and kept at the testing temperature.

3

4

5

\subsection{Joint preparation and lap shearing strength testing}

After surface treating with different sandpaper, the aluminum sheets were cleaned by acetone with an ultrasonic cleaner for 20 minutes. Then the sheets were dried in the air at room temperature for 4 hours. Adhesive was uniformly daubed on the aluminum surface using a hand-held injection gun. In order to control the adhesive thickness, two copper wires with $\Phi 0.3 \mathrm{~mm}$ are inserted into the adhesive layer. The adhesive area was $25 \mathrm{~mm}$ in width and $12.5 \mathrm{~mm}$ in length. A C-type flat-mouth fixture was used to clamp the aluminum substrates and adhesive together at a pressure of $0.2 \mathrm{MPa}[\underline{26}]$. After assembly, the redundant adhesive beyond the bonding area was removed. Finally, the adhesively bonded joints were cured for half a minute in a drying oven at $180 \pm 0.2{ }^{\circ} \mathrm{C}$.

Lap shearing test which is a widely used joint test for automobile parts [27], was conducted to investigate the effect of the different surface roughness of the aluminum substrates on the shear strength of the adhesively bonded joints. It was performed through the tensile testing standard after curing. The parameters setting referred to the standard ASTM D1002-2001. In order to ensure that the force direction is maintained in a straight line during the test, and to decrease bending stress generated, a shim was pasted with at the end of each aluminum sheet of the joint. The total shim thickness was the total of the thickness of the aluminum substrate and the adhesive layer, namely 4.1 mm. Detailed parameters of the adhesively bonded joints for lap shearing strength testing are shown in Fig. 2. The testing was carried using an Instron 3369 tensile testing 
1 equipment, and the load-displacement curves were acquired, and the loading speed is 5

$2 \mathrm{~mm} \cdot \mathrm{min}^{-1}$. The maximum load in load-displacement curve was applied to estimate the

3 lap shearing strength. Tensile tests were performed on three joints for each parameter in

4 Table 1, and the average strength was considered as the ultimate result. Lap shearing

5 strength of the joints was calculated on the basis of Eqs. (7)

6

$$
\sigma=F_{M A X} /(\mathrm{L} \times W)
$$

7 where $\sigma$ represents the lap shearing strength of the joints; $F_{M A X}$ represents the peak

8 loading force; and $L=12.5 \mathrm{~mm}$ represents the length of the bonding area, and $W=25$

$9 \mathrm{~mm}$ represents the bonding the width of the bonding area. After stretching, the fracture

10 surface of all test joints was analyzed after failure.

11

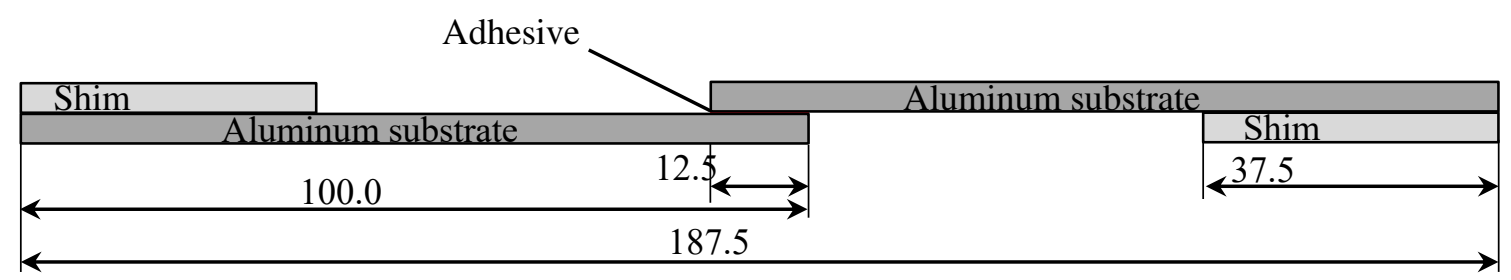

Fig. 2. The specimen parameters of aluminum alloy adhesively bonded joints (unit: $\mathrm{mm}$ )

\section{Results and discussion}

\subsection{Surface roughness testing results}

Fig. 3 indicates the surface roughness measurement results, namely of surface roughness $R_{a}$ and $R_{z}$ of the aluminum sheets before and after sandpaper grinding. It can

17 be observed that the substrate surface is apparently roughened after grinding. The

18 largest values of $R_{a}$ and $R_{z}$ of the specimens treated by sandpaper (A-1) are $2.06 \mu \mathrm{m}$ and

$19 \quad 13.74 \mu \mathrm{m}$, respectively, which are as high as 7.1 times and 4.8 times that of the un- 
1 grinded simples (S-0), respectively. The $R_{a}$ and $R_{z}$ of specimens decrease as the mesh

2 number of sandpaper increases. In general, the smaller the sandpaper mesh number is,

3 the larger the particle size will be. When the sandpaper mesh number turned from P80

4 to P800, the average variation of $R_{a}$ and $R_{z}$ increased $1.54 \mu \mathrm{m}$ and $9.81 \mu \mathrm{m}$,

5 respectively.
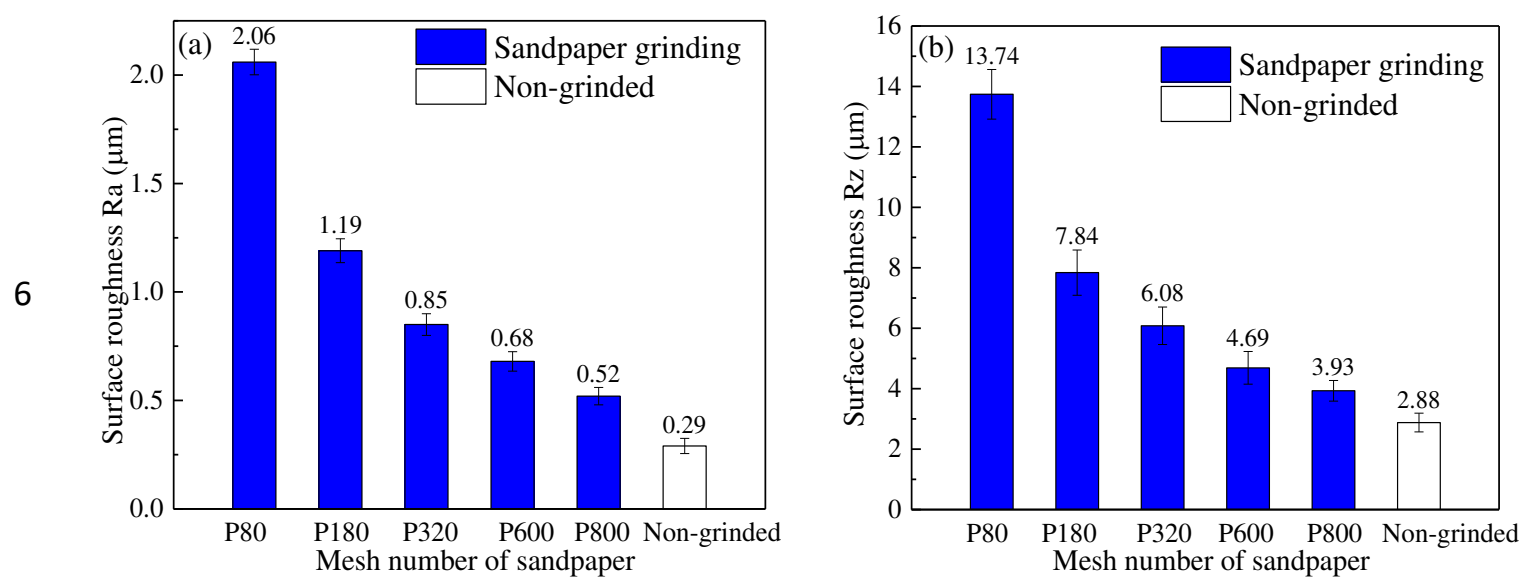

Fig. 3. Effect of sandpaper grinding parameters on surface roughness (a) Ra and (b) Rz

\section{$8 \quad 3.2$ Lap shearing test results}

The lap shearing test results are the most directional reflection of the mechanical

behavior of the adhesively bonded joints. Fig. 4 demonstrates the lap shearing strength of the adhesively bonded joints made of the aluminum sheets with different surface roughness values. The maximum profile height $R_{z}$ is used in this study. As demonstrated in Fig. 4, the lap shearing strength of the joints firstly increases and then slightly decreases with the surface roughness. Compared to the joint made of un-grinded sheets, the lap shearing strength of the joints made of grinded sheets shows a great improvement. It increases rapidly from 19.3 $\mathrm{MPa}$ to $30.4 \mathrm{MPa}$ (an increase of 57.5\%), when the surface roughness increases from $2.88 \mu \mathrm{m}$ (un-grinded samples) to $6.08 \mu \mathrm{m}$ 
1 (grinded by sandpaper with mesh number of P320). Then with the surface roughness of

2 the aluminum substrate increase, the shearing strength of the joints decreases. When the

3 surface roughness of aluminum is $6.08 \mu \mathrm{m}$, the maximum shearing strength of the joint

4 is $30.4 \mathrm{MPa}$, which increases by $9.7 \%$, compared to the joints with the surface

5 roughness of $3.93 \mu \mathrm{m}$, and increases by $57.5 \%$, compared to the joints with the surface

6 roughness of $2.88 \mu \mathrm{m}$. In this condition, the lap shearing strength of the joints reaches

7 about $82 \%$ of that of the structural adhesive which is about $37.1 \mathrm{MPa}$. Lap shearing

8 strength decreases when the joints of surface roughness exceed $6.08 \mu \mathrm{m}$. For example,

9 the lap shearing strength of the joints were made of the sheets with surface roughness of

$13.74 \mu \mathrm{m}$ is $26.7 \mathrm{Mpa}$, which is $12.2 \%$ lower than that of the joints made of the sheets whose surface roughness is $6.08 \mu \mathrm{m}$.

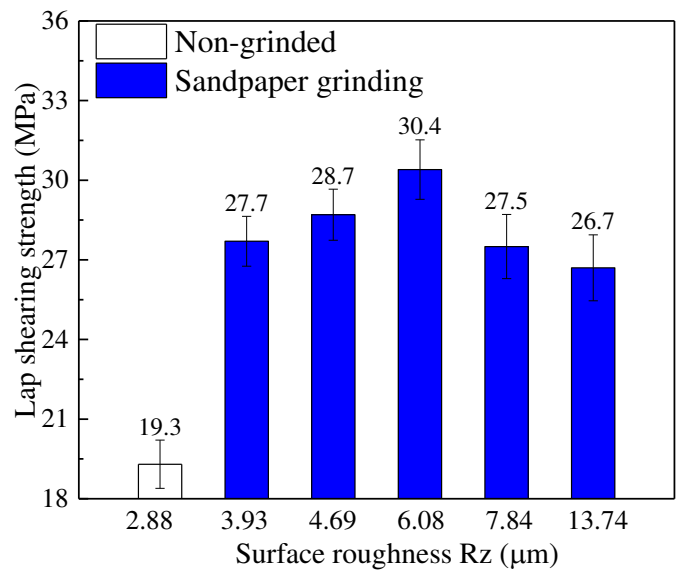

Fig. 4. lap shearing strength changes with surface roughness

\subsection{The Effect surface roughening on the lap shearing strength of the joints}


1 mechanism, the surface morphology of the aluminum substrates treated with sandpapers

2 of different mesh numbers were observed and compared. The surface morphology

3 images are presented in Fig. 5. Many parallel valleys are recorded on the surface of the

4 grinded aluminum substrates, and width and depth of these valleys decrease with the

5 increase of the sandpaper number mesh. The surface morphology of the un-grinded

6 sheets is also shown in Fig. 5, in which the color of surface images is lighter compared

7 to the grinded sheets. It means that the un-grinded specimen has a flat surface, and

8 exhibits a small surface roughness value. For the surface characteristics of grinded

9 sample as shown in Fig. 5, the morphology color brightens dramatically and the scratches depth increases with the surface roughness of sheets increases.

As shown by Fig. 4, the picture shows that surface roughness significantly affects the lap shearing strength of the adhesive bonded joints significantly. When the surface roughness of the grinded aluminum substrates is $6.08 \mu \mathrm{m}$, the lap shearing strength is

$57.5 \%$ higher than that of the joint made of the sheets whose surface roughness is 2.88

$\mu \mathrm{m}$. The reason is that when the aluminum substrates were grinded by sandpaper, grooves, ridges and other uneven flats were produced on the substrate surface, as shown in Fig. 5(d). It prevents the adhesive from detaching the aluminum substrates. In this way, surface roughening improves the lap shearing strength of joints greatly. The roughening grade also significantly affects the lap shearing strength of the joints. When the aluminum substrate surface roughness made of the sheet is $6.08 \mu \mathrm{m}$, the lap shearing strength is $30.4 \mathrm{MPa}$, which is $9.7 \%$ higher than that of the joints made of the sheet whose surface roughness is $3.93 \mu \mathrm{m}$. The reason is that when the aluminum substrates 
1 were grinded by the coarse sandpaper, so that several hollows were formed on the

2 aluminum substrates surface. The grooves become wider and deeper, and the ridges

3 become wider and higher (illustrated in Fig. 5(b) and (d)). The greater the height

4 difference between the grooves and the ridges is, the more difficult to separate the

5 adhesive from the aluminum substrates will be [23]. It was found that the grinded

6 surface exhibit uniform grooves and ridges surface pattern, as shown in Fig. 5. Grooves

7 and ridges offer more micro surface area for bonding, and increase the opportunities for

8 the adhesive to permeate into the grooves. However, it weakens the interlocking effect

9 of the surface features when the raw sheets were grinded by P800 and un-grinded

10 samples. Therefore, to a certain extent, roughening the aluminum substrate surface

11 enhances the lap shearing strength of the joints.
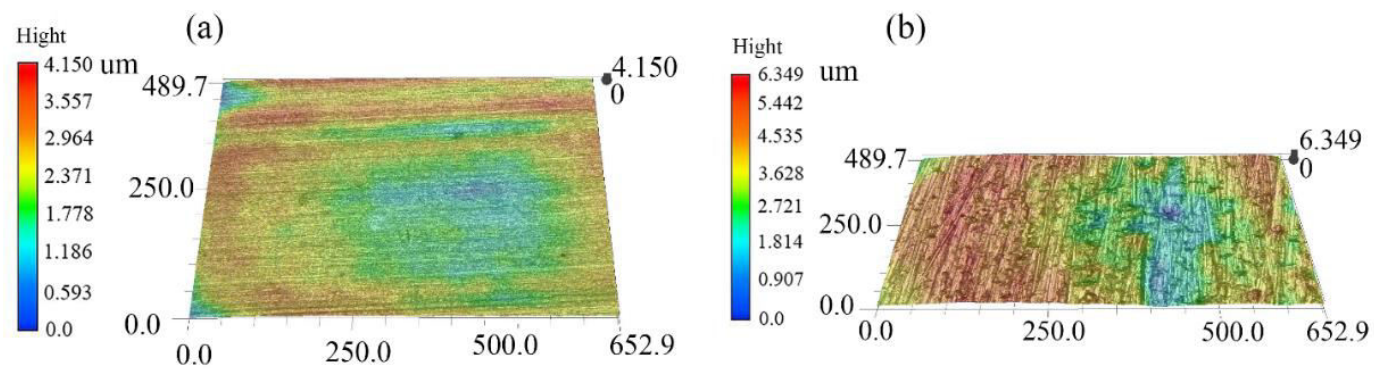

12
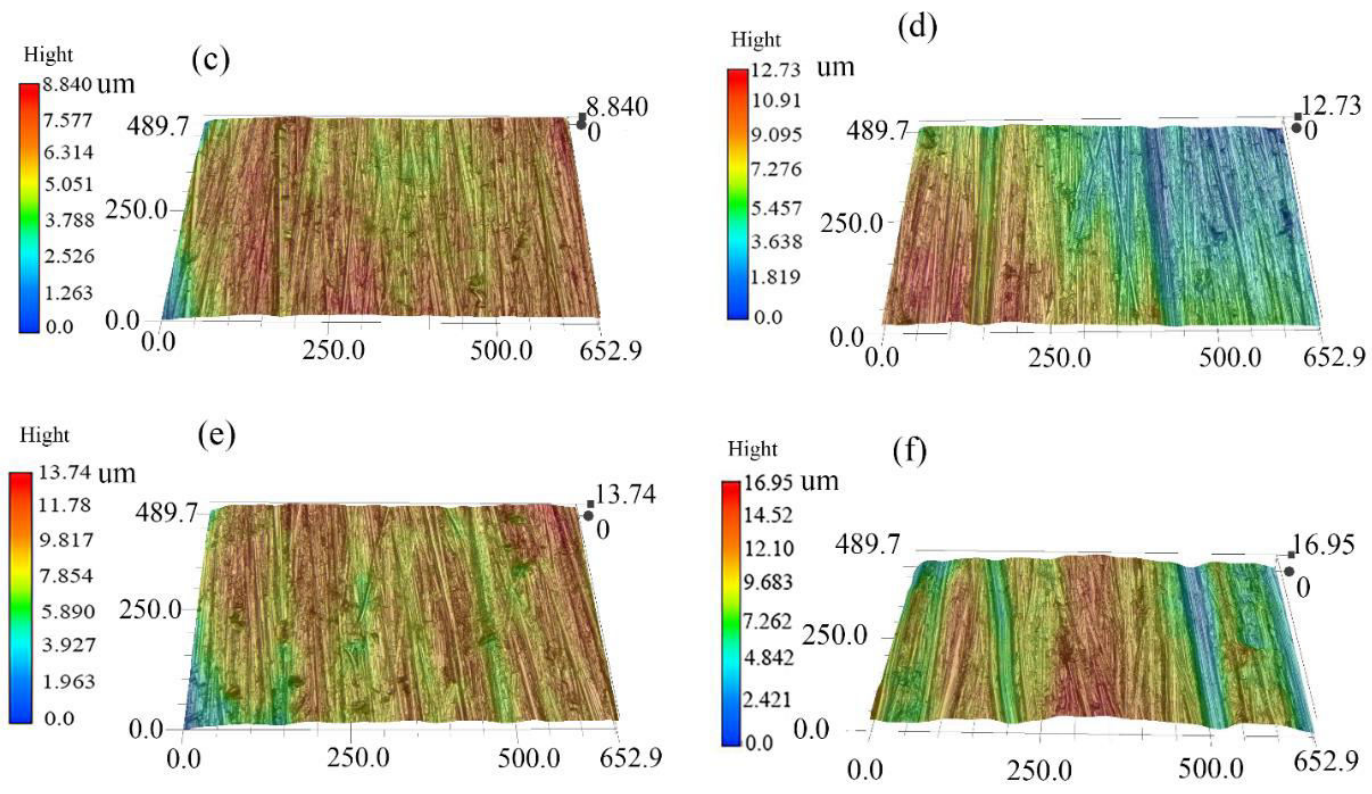
Fig. 5. Surface morphology images of aluminum sheets before and after grinding with different that the grinding surface morphologies have a significant effect on the shearing strength.

5 As demonstrated in Fig. 6 and Fig. 7, surface roughening obviously increases the 6 interfacial area ratio. As a result, the number of bonding points at the contact area

7 between the adhesive and aluminum substrates increases remarkably. In addition, a 8 large number of anchors allow the adhesive to permeate the surface of the aluminum substrate, and then the adhesive is interlocked with the substrate in the groove during curing. Because the grinding process modifies the amount of interaction between the substrates and adhesive, surface roughening increases the mechanical interlocking effect. In Fig. 6, the fluctuation of un-grinded samples profile curve is lower than that of the grinded samples. In the cases, when the surface roughness values are $2.88 \mu \mathrm{m}$ and 6.08 $\mu \mathrm{m}$, the mean depth of the grooves aluminum substrates are approximately $0.02 \mu \mathrm{m}$ and $4 \mu \mathrm{m}$, respectively. Moreover, the rougher the aluminum substrate is, the stronger the fluctuation of the surface profile becomes. When the surface was not grinded, the surface profile is nearly a straight line. However, as seen from Fig. 6(b) to Fig. 6(f), the surface profiles are dramatically fluctuant curves when the samples were grinded by sandpapers. To better clarify the influence of anchoring of adhesively bonded joints, the cross-section of the bonded samples was examined. Fig. 7 lists the cross-section morphology of the adhesively bonded joints made of the sheet without grinding sheets (a), smaller roughness (b), moderate roughness (c), and larger roughness (d), which has 
1 that the cross-section of Fig. 7(a) shows a nearly straight line, and the cross-section of

2 Fig. 7(d) shows a sawtooth shape. The difference of two types of cross-sections leads to

3 different surface roughness. Combined with Fig. 4, the lap shearing strength of the

4 bonded joints made of grinded sheets is higher than that of joints made of un-grinded

5 sheets. This is related to the stronger anchor effect of the surface morphologies

6 originated from larger contact areas [13]. With larger anchor sizes, it is much more

7 difficult for the adhesive to separate from the aluminum substrates. Analyzing the other

8 samples were grinded by sandpaper, the same effect can be summarized when the

9 surface roughness values are below $6.08 \mu \mathrm{m}$.
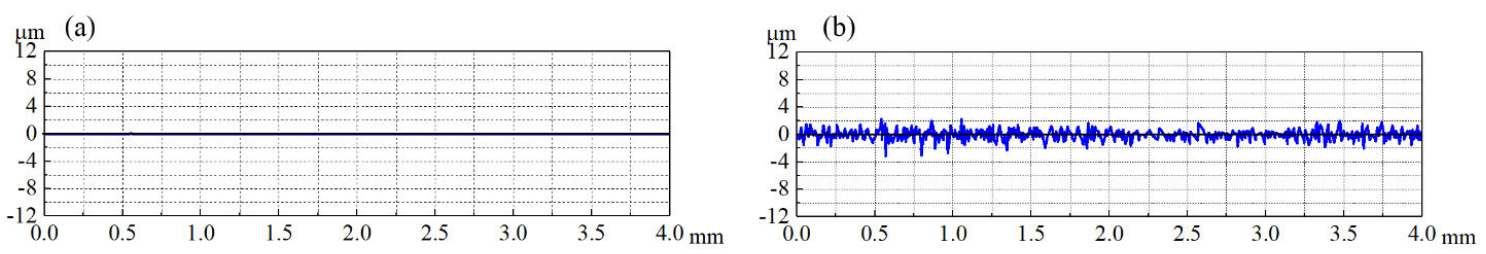

10
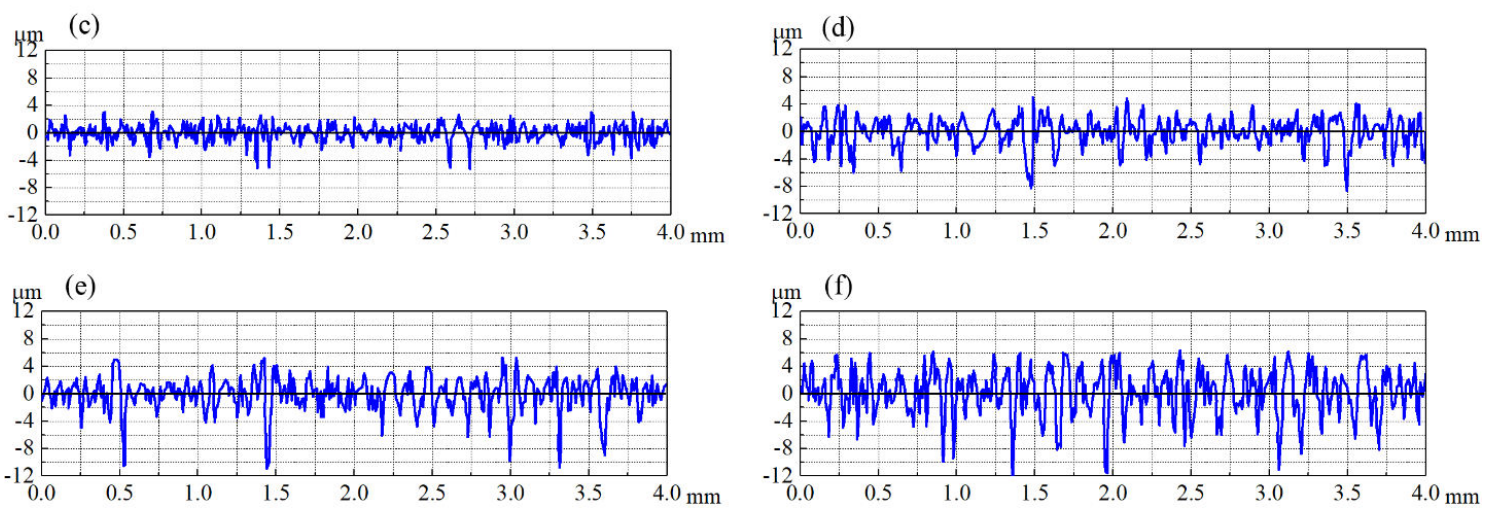

Fig. 6. The surface roughness profile of aluminum substrates with various surface treatment (a)

un-grinded, (b) P800, (c) P600, (d) P320, (e) P180, (f) P80 

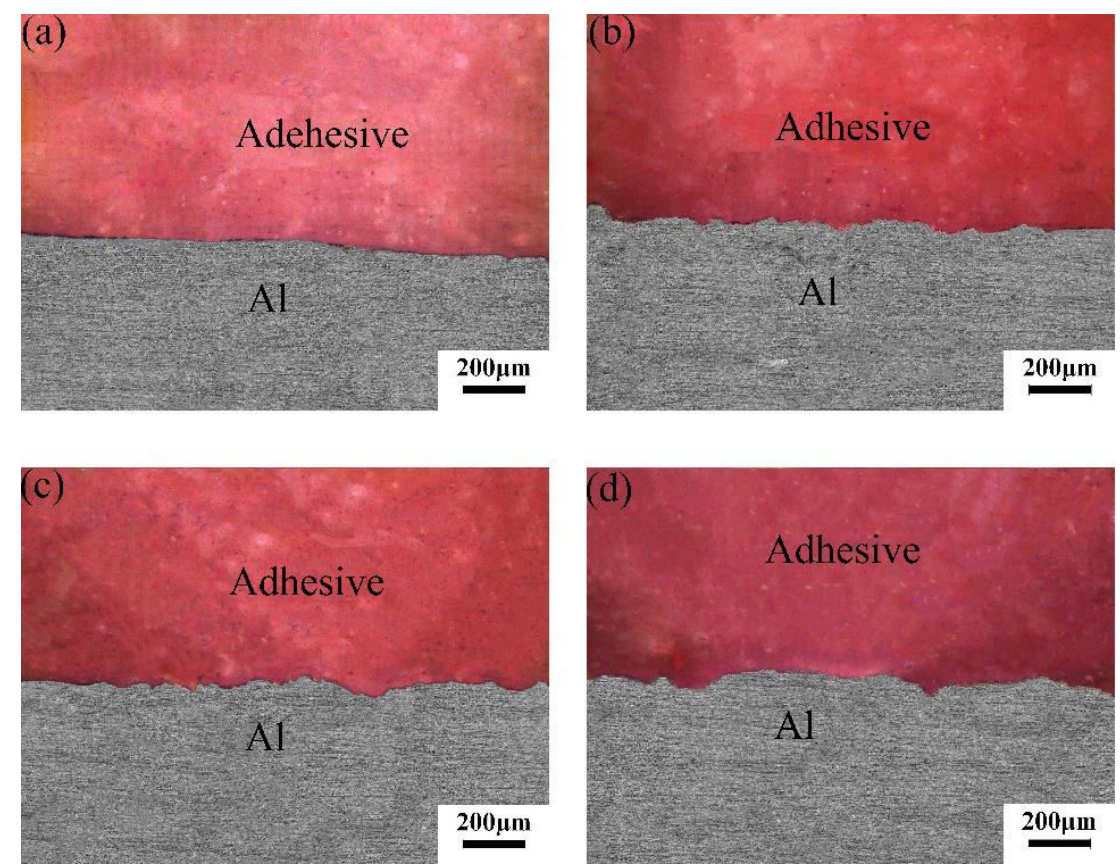

Fig. 7. Optics microscope (OM) images of the adhesively bonded joints cross-section with various surface treatment (a) un-grinded; (b) P800; (c) P600; (d) P320.

\subsubsection{Influence of grinding on the surface area of the raw materials}

Fig. 8 shows the change of microcosmic surface area for grinded sheets compared to un-grinded sheets. It is obviously examined that the microcosmic surface area value of samples grinded by sandpaper is apparently higher than that of un-grinded samples.

The microcosmic surface area of un-grinded sheets is $3.2 \times 10^{5} \mu \mathrm{m}^{2}$. The higher surface roughness of aluminum substrates is, the larger microcosmic surface area will be. Besides, when the surface roughness is $3.93 \mu \mathrm{m}$ and $13.74 \mu \mathrm{m}$, its microcosmic surface area increment is $3 \times 10^{5} \mu \mathrm{m}^{2}$ and $19 \times 10^{5} \mu \mathrm{m}^{2}$, respectively. These results indicate that surface roughening can increase the microcosmic area of the aluminum substrate. Furthermore, combined with Fig. 4, it is clear that the lap shearing strength of grinded samples with a rougher surface is greater than that of un-grinded samples when the $R_{z}$ is between $2.88 \mu \mathrm{m}$ and $6.08 \mu \mathrm{m}$. This is related to that surface roughening improves 
1 effective contact areas in grinded samples. Due to the existence of grooves and ridges

2 on the substrate surface, there is more micro surface area for bonding. Therefore, the

3 larger the effective contact area is, the weaker the stress concentration will form, and the

4 adhesively bonded joints are difficult to be damaged [13]. Similar trends were observed

5 in average roughness and microcosmic surface area when the $R_{z}$ is between $2.88 \mu \mathrm{m}$ and

$6 \quad 13.74 \mu \mathrm{m}$, which proves that the enhanced adhesion caused by mechanical grinding

7 resulting from the increasement of surface area. However, the lap shearing strength of

8 the joint is not a linear relationship with the microcosmic surface area.

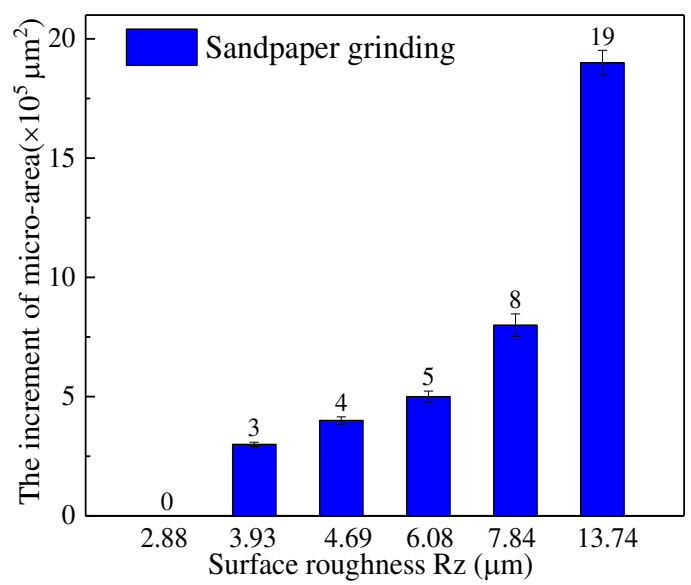

Fig. 8. The increment of microcosmic surface area for grinded sheets compared to un-grinded sheets

\subsubsection{Influence of grinding on the surface free energy of the raw materials}

In order to find out the reasons why the lap shearing strength of the joint does not increase monotonically with the surface roughness increasing, the interfacial adhesion situations of the joints with grinded aluminum substrates surface were investigated. Wettability is an important index to evaluate interfacial adhesion situations, which can help engineers to comprehend the interaction mechanism between the adhesive and substrate. Wetting behavior of the adhesive on the aluminum sheets with different 
1 surface morphology, and roughness was analyzed based on the method reported in the

2 literature [28]. Fig. 9 shows the average water contact angles and diiodomethane contact

3 angles on the aluminum substrate surface after grinding with the different number mesh

4 sandpaper, respectively. As the surface roughness of aluminum substrate increases, the

5 surface contact angle decreases firstly and then increases gradually in the test liquid

6 using both water and diiodomethane. Furthermore, when the surface roughness of the

7 aluminum substrate is $2.88 \mu \mathrm{m}$, the water contact angle is $67.21^{\circ}$, and then it decreases

8 dramatically when the surface roughness turns from $2.88 \mu \mathrm{m}$ to $6.08 \mu \mathrm{m}$, and further

9 drops to $42.25^{\circ}$ when the surface roughness increases to $6.08 \mu \mathrm{m}$. After that, when the

surface roughness is $13.74 \mu \mathrm{m}$, the water contact angle grows quickly to about $53.94^{\circ}$.

11 The changing trend of the diiodomethane contact angle is the same as that of water.

12 When the surface roughness of the aluminum substrate is $2.88 \mu \mathrm{m}$, the diiodomethane contact angle is $47.18^{\circ}$, It drops to $27.97^{\circ}$ when the surface roughness increases from $2.88 \mu \mathrm{m}$ to $6.08 \mu \mathrm{m}$. After that, the diiodomethane contact angle grows quickly to about $35.78^{\circ}$ when the surface roughness of the aluminum substrate reaches to $13.74 \mu \mathrm{m}$. The water contact angles and diiodomethane contact angles on the grinded aluminum

17 substrate are significantly lower than that of un-grinded samples. According to Eq .(1), the smaller the contact angle of the aluminum substrate means it has higher $W_{a}$ and better wettability. The wettability firstly becomes better and then goes worse with the surface roughness increasing. Surface wettability of the samples is deeply affected by the surface roughness. When surface roughness exceeds $6.08 \mu \mathrm{m}$, the wettability and 
1 interfacial bonding effect become poor, which results in the lap shearing strength 2 decrease.
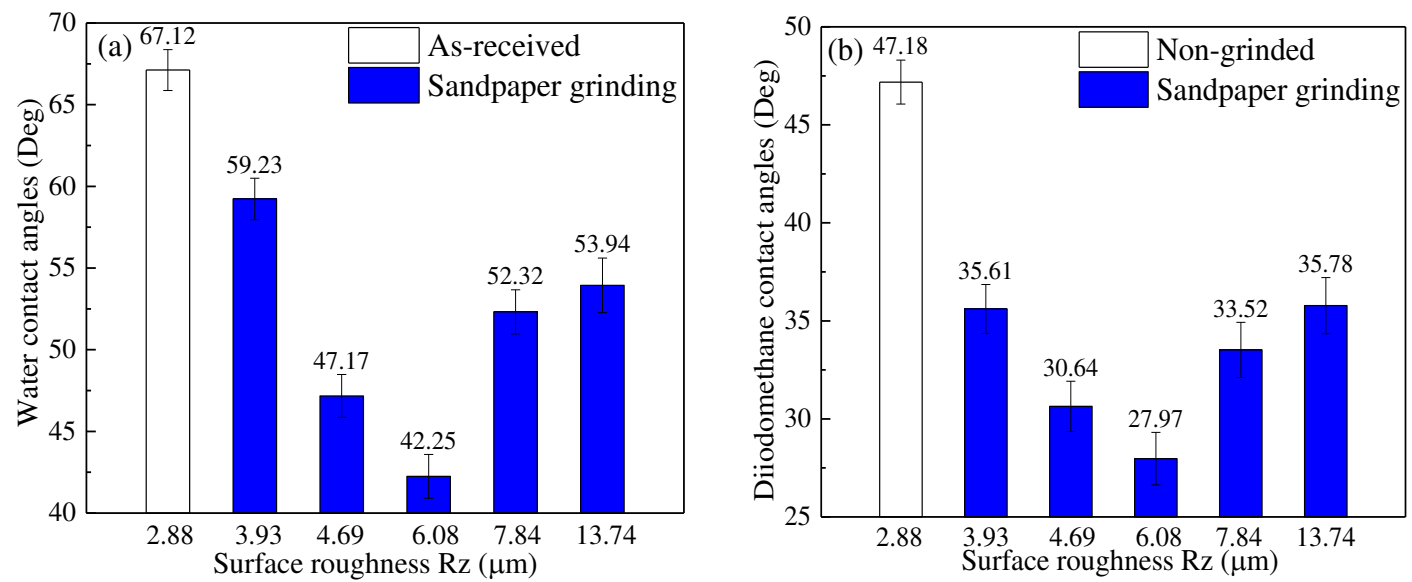

4 Fig. 9. The contact angle of testing liquid with different surface roughness (a) water (b)

5 diiodomethane

6 The contact angles of the $1840 \mathrm{C}$ structural adhesive at $180{ }^{\circ} \mathrm{C}$ on the aluminum

7 substrate with different surface roughness values are shown in Fig. 10. It can be found

8 that the changing trend of adhesive contact angle is consistent with that of water and

9 diiodomethane. When the surface roughness increases from $2.88 \mu \mathrm{m}$ to $6.08 \mu \mathrm{m}$, the adhesive contact angle decreases from $66.2^{\circ}$ to $55.4^{\circ}$. Meanwhile, the wettability of the aluminum substrates increases with the surface roughness increasing. The fact is that the interfacial area both in the substrate and adhesive is largely increased. When the surface roughness of the substrate reaches to $6.08 \mu \mathrm{m}$, the aluminum substrate has the best wettability. The infiltration of the adhesive on a metal substrate was affected by many factors, for example, the geometry of the dimples, the surface free energy and the rheology of the adhesive. For the adhesively bonded aluminum joints, even if the oils and organic contaminants of the substrate surface are removed, the spreading of adhesive on the aluminum substrates surface is difficult because the surface free energy 
1 of the substrates is very low, Therefore, the adhesive cannot infiltrate every corner of 2 the aluminum substrate surface.

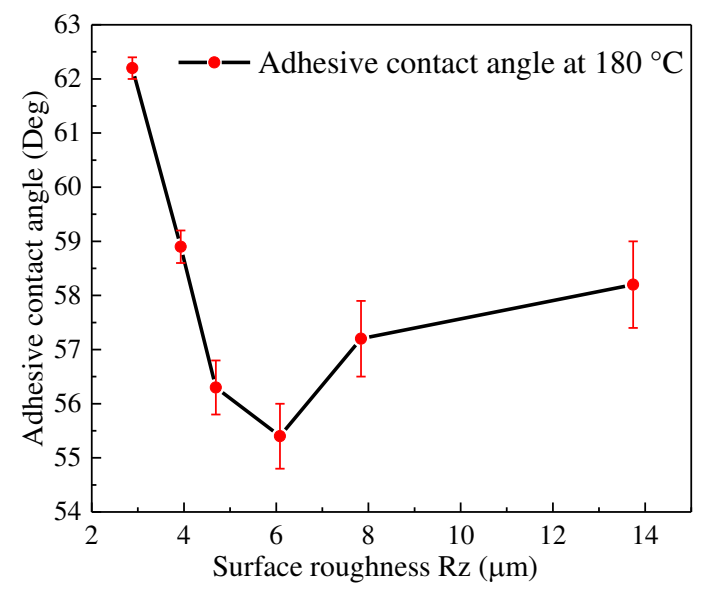

Fig. 10. The adhesive contact angle with different surface roughness at $180^{\circ} \mathrm{C}$

According to the absorption theory, the surface and interfacial energies are related to the interfacial strength between the substrate and the adhesive, which influences the strength of the adhesively bonded joints $[\underline{29}, \underline{30}]$. Fig. 11 shows the influence of the surface roughness on the surface free energy and its component calculated according to Eq. (1) and Eq. (2). From these results, it seems that the surface free energy of the aluminum substrate has the opposite change trend compared to the surface contact angle with the increase of surface roughness. However, the surface free energy of aluminum substrates and the lap shearing strength of the adhesively bonded joints have the same change trend with the surface roughness increase. The dispersion component (diiodomethane) and polar component (water) of surface free energy of various samples are apparently different from each other. The polar components (water) surface free energy is generally lower than that of the dispersion components (diiodomethane). Although there is no obvious relationship between the surface free energy and surface roughness, the surface free energy of the dispersion component (water) is much closer 
1 to the total surface free energy. One reason is that polar elector-donor interactions

2 decrease with the surface roughness and the nonpolar dispersion interactions do not rely

3 on the surface morphology. The adhesive adsorption theory holds the opinion that

4 bonding is the use of mechanical bonding force, chemical bonding force and physical

5 adsorption force between the interfacial connecting materials. Because the electronic

6 polarity of the adhesive and aluminum substrate attracts each other to produce a

7 bonding force, the adhesively bonded joints become stronger, which leads to less

8 interfacial failure area. As a result, the failure percentage of the interfacial contact area

9 initially decreases and then increases with the surface roughness, as shown in Fig. 6.

10 Therefore, in view of the adhesive adsorption theory, the changing trend of interfacial

11 failure percentage is opposite to that of the lap shearing strength with the surface

roughness. Similarly, the lap shearing strength of the adhesively bonded joints firstly increases and then gradually decrease as the surface roughness increases according to the theory. Generally, with the increase of surface roughness of the sheets, the surface free energy calculated by the water contact angle decreases. Moreover, the polar component of the surface free energy increases from $35.83 \mathrm{~mJ} / \mathrm{m}^{2}$ to $45.03 \mathrm{~mJ} / \mathrm{m}^{2}$ when

17 the surface roughness of the aluminum substrate increases from $2.88 \mu \mathrm{m}$ to $6.08 \mu \mathrm{m}$. In all cases, the aluminum substrate surface was grinded by the different number mesh of sandpaper, and the percentage of the polar component of surface free energy is greater than that of the dispersive component. These results are consistent with the previous studies $[\underline{24}, \underline{31}]$. The surface free energy values of the sample with surface roughness of 
1 roughness is $3.93 \mu \mathrm{m}$ and $6.08 \mu \mathrm{m}$, respectively. Meanwhile, the surface free energy of

2 the sample with a surface roughness of $13.74 \mu \mathrm{m}$ is $56.69 \mathrm{~mJ} / \mathrm{m}^{2}$, which is $12.9 \%$ lower

3 than that of the sample when the surface roughness is $6.08 \mu \mathrm{m}$. Thus, when the surface

4 roughness of aluminum sheets is $6.08 \mu \mathrm{m}$, it has the highest surface free energy. As

5 pointed out by Harris and Beevers [르], smoother sandblasting surfaces have higher

6 surface free energy. Furthermore, Hitchcock et al. [33] examined that the surface

7 roughness of the substrate usually leads to the decrease of wettability in a certain range,

8 too. Some researchers found out that the asperities, ridges and peaks, on the surface of

9 the substrates produce obstacle to prevent droplet diffusion [ $[\underline{34}, \underline{35}]$. Thus, over roughening surface greatly decreases the surface free energy of the aluminum substrates, and reduce the lap shearing strength of adhesively bonded joints.

According to Eq. (3) and (4), the adhesion energy of adhesive/aluminum substrate is calculated by combining the surface free energy of the adhesive and the test contact angle. The results are shown in Table 3 and Fig. 11. The simplified zero diffusion pressure is the premise for calculating the adhesion work in ambient air using Eq. (3). Because the work of adhesion, $W_{a}$, determines the status that adhesive penetrating into the substrate, the bonding work has a significant impact on the diffusion of the adhesive. When the bonding joints are heated to $180^{\circ} \mathrm{C}$, this temperature is also the curing temperature of the adhesive. The adhesive will form a specific contact angle on the surface of the aluminum plate to wet the aluminum substrate. The contact angle of the adhesive on the aluminum substrate is $55.4^{\circ} \pm 0.8^{\circ}$. According to the reference [ $\underline{36}$, the surface free energy of structural adhesive at room temperature is $65.06 \mathrm{~mJ} / \mathrm{m}^{2}\left(\gamma_{s}=\gamma_{s}^{p}+\right.$ 
$1 \gamma_{s}^{d}=20.03 \mathrm{~mJ} / \mathrm{m}^{2}+45.03 \mathrm{~mJ} / \mathrm{m}^{2}$ ). Then, according to the test value of contact angle

$2\left(55.4^{\circ}\right)$ and the surface free energy of the structural adhesive $\left(65.06 \mathrm{~mJ} / \mathrm{m}^{2}\right)$, and the

3 adhesion work between aluminum substrate and adhesive is $102.14 \mathrm{~mJ} / \mathrm{m}^{2}$ calculated by

4 Eq. (1).

5 The work adhesion increases with increasing surface roughness in the range from

$62.88 \mu \mathrm{m}$ to $6.08 \mu \mathrm{m}$. One factor improving the lap shearing strength is that the

7 mechanical interlocking effect of the metal substrates. In order to achieve a good

8 mechanical interlock effect between the adhesive and the substrate, a perfect infiltrating

9 of the adhesive into the irregular corners or the grooves on the substrate surface is

10 necessary. Consequently, surface roughening produces adhesive interfacial adsorption

11 that can improve the mechanical interlock effect. Another significant factor which

12 promotes the bonding strength is that a satisfied adhesion work is needed, although its

13 value is quite lower than that of the actual separation work. Because of the tested value

14 of the adhesion work $W_{a}=102.14 \mathrm{~mJ} / \mathrm{m}^{2}$ in the adhesive/aluminum bonding system is

15 higher than $65.06 \mathrm{~mJ} / \mathrm{m}^{2}$, it is sufficient to produce a mechanical interlocking. Under

16 this condition, the adhesive can completely flow into all corners of the micro roughened

17 aluminum substrate.

18 Table. 3 Surface free energy and its components for substrates with different surface roughness

\begin{tabular}{cllllll}
\hline$R_{z}(\mu \mathrm{m})$ & 2.88 & 3.93 & 4.69 & 6.08 & 7.84 & 13.74 \\
\hline$\gamma_{s}^{p}\left(\mathrm{~mJ} / \mathrm{m}^{2}\right)$ & 35.83 & 41.74 & 43.95 & 45.03 & 42.71 & 41.66 \\
$\gamma_{s}^{d}\left(\mathrm{~mJ} / \mathrm{m}^{2}\right)$ & 10.06 & 12.14 & 17.86 & 20.03 & 15.53 & 15.03 \\
SFE $\left(\mathrm{mJ} / \mathrm{m}^{2}\right)$ & 45.89 & 53.88 & 61.81 & 65.06 & 58.24 & 56.69 \\
\hline
\end{tabular}

*Note: SFE is short for surface free energy. 


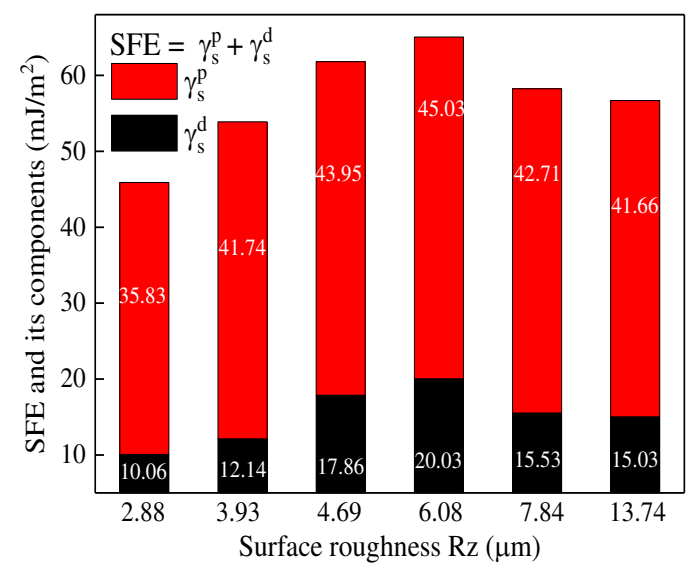

2

3

4

5

6

7

8 However, the mixed failure mode refers to some cohesive failure and some interface

9 failure. In practical application, most of them are mixed failure mode. In this way, the

Fig. 11. Surface free energy and its components for different aluminum substrates after grinding

\subsection{Failure behavior of the adhesively bonded joints}

The failure mode of adhesively bonded joints after the tensile test usually includes three categories, namely the cohesive failure, interfacial failure, and mixed failure modes [37]. Cohesion failure is a fracture of the adhesive itself. The interfacial failure mode is defined as the adhesive is completely separated from the substrate surface. engineers try to make the most of the mechanical performance of the structural adhesive. The failure patterns of adhesively bonded joints after the test are shown in Fig. 12. The joint made of un-grinded sheets have the biggest interfacial failure area among all the different treatment parameters joints after lap shearing tests. Moreover, the interface failure area initially decreases and then increases with the surface roughness increases. When the surface roughness of aluminum sheet is $6.08 \mu \mathrm{m}$, the interface failure area rarely exists in the failure pattern. Compare to the failure pattern of 
1 other treatment parameters joints, the number of bare regions in the fractured surface is

2 the least.
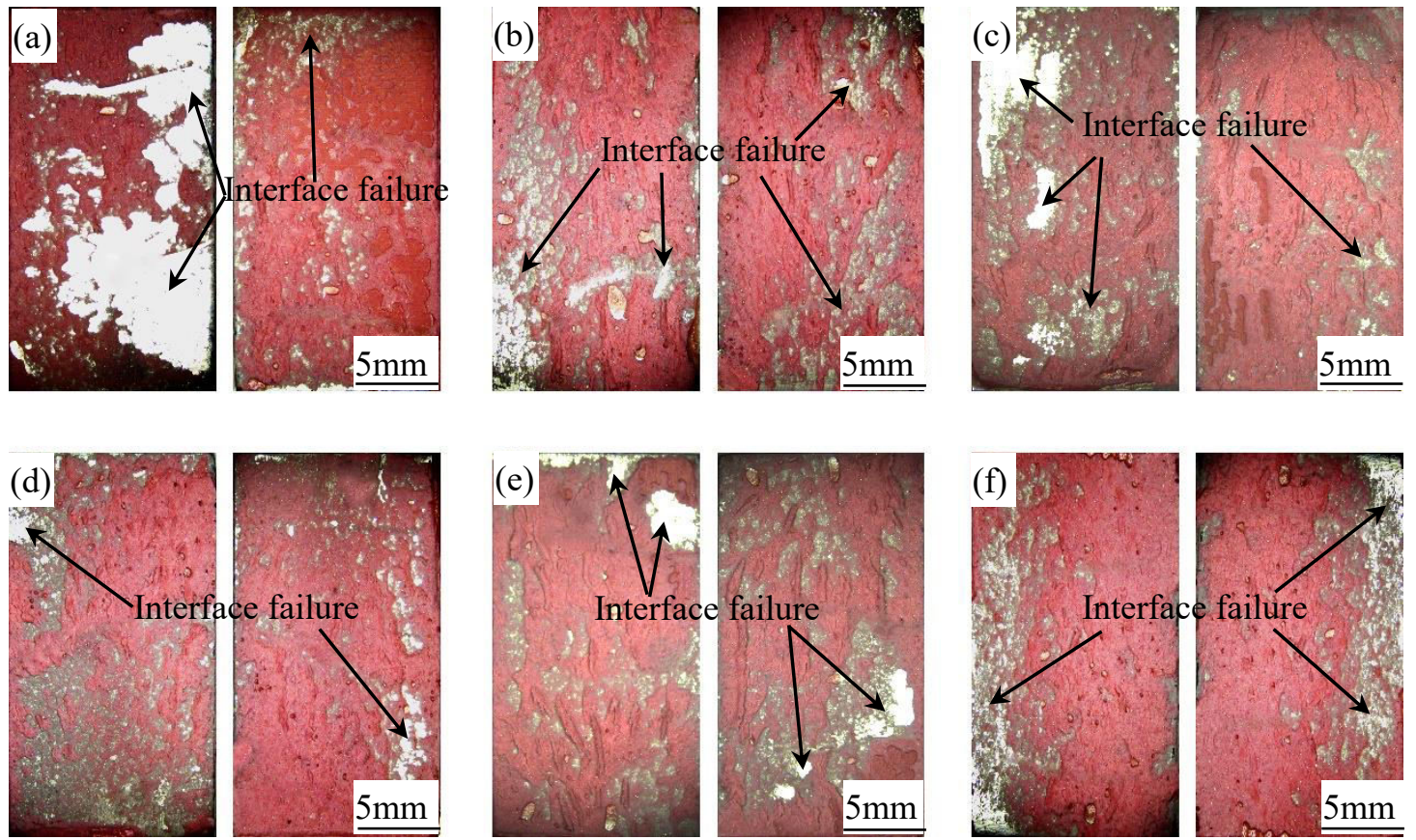

Fig. 12. The macro-morphology of fractured surface with different mesh number of sandpaper

(a) un-grinded; (b) P800; (c) P600; (d) P320; (e) P180; and (f) P80.

The interface failure area percentages of the adhesively bonded joints is

7 demonstrated in Fig. 13. With the surface roughness of the aluminum substrates

8 increases, the percentage of interface failure area of adhesively bonded joints initially

9 decreases drastically and then increases slightly. The percentage of interface failure area

of the joint made by the substrates with surface roughness of $9.8 \mu \mathrm{m}$ drops by $76.4 \%$

approximately, compared to the adhesively bonded joints made of un-grinded substrates.

12 It indicates that the surface roughening reduces the percentage of interface failure significantly and enhances the lap shearing strength. In addition, the smaller the

14 interface failure percentage is, the stronger the adhesively bonded joints strength will

be. When the surface roughness is $6.08 \mu \mathrm{m}$, the adhesively bonded joints have the 
1 smallest interface failure area, which decreases by $92.5 \%$ and $68.3 \%$ for those bonded

2 joints with the surface roughness of 2.88 and $13.74 \mu \mathrm{m}$, respectively.

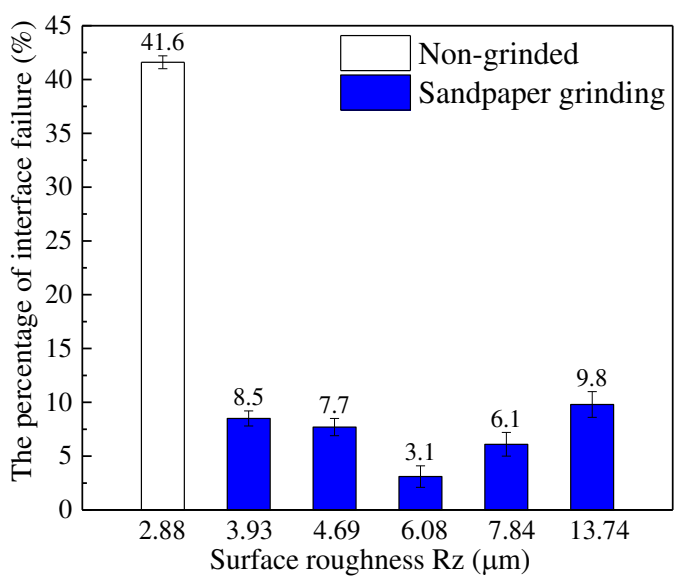

Fig. 13. The bare area on the fracture surface

\section{$5 \quad 3.5$ Influence of over roughening on the failure behavior of the joints}

6

As illustrated in Fig. 4, the lap shearing strength decreases apparently when the surface roughness turns from $6.08 \mu \mathrm{m}$ to $13.74 \mu \mathrm{m}$. In another word, over roughening surface of raw materials is harmful to the interfacial adhesion state of joints crosssection. Fig. 14 depicts the OM images of the adhesively bonded joints cross-section with coarse surface treatments (grinded by P80 and P180). It can be seen that over roughening produces micro-cracks at the interfacial region, which is consistent with the previous studies $[\underline{23}, \underline{38}]$. These defects will lower the effective contact area so that lap shearing strength decreases. Moreover, the extremely uneven surface prohibits the adhesive in freely spreading on the substrate surface. Based on the information mentioned above, taking adhesively bonded joints as examples, Fig. 15 depicts a mechanism diagrammatic of the cross-section of the joints with different surface roughness. Fig. 15(a) shows the mechanism diagram of the bonding status of the coarse 
1 interface, indicating the samples grinded by sandpaper with the P80 and P180, whose

2 surface roughness is greater than that of the other three treatment methods and un-

3 grinded, but the bonding status is extremely bad, meaning their mechanical interlocking

4 effect is very terrible. Some reasons are concluded as below: (i) the profiles were

5 disorder and nonuniform on the micro-scale aluminum substrate surface, as shown in

6 Fig. 6. It will cause the adhesive to be irregularly distributed on the aluminum substrate

7 surface. (ii) Because air gas is trapped in the valleys, over roughening substrate surface

8 prevents the adhesive from wetting the coarse surface of the aluminum substrate

9 completely. (iii) Because of insufficient wettability and residual air between the aluminum substrate and the adhesive, the corners and grooves on the substrate surface cannot entirely saturated with adhesive before solidification. Those factors reduce the valid bond area and create stress concentration at the interfacial region. As a result, when the aluminum substrate surface is grinded by P80 or P180, the surface is coarse, and a lot of underfill areas of the joints will be formed, and an alternating solid-liquid and gas-liquid interface will also gradually appear as shown in Fig. 14 and Fig. 15(a).
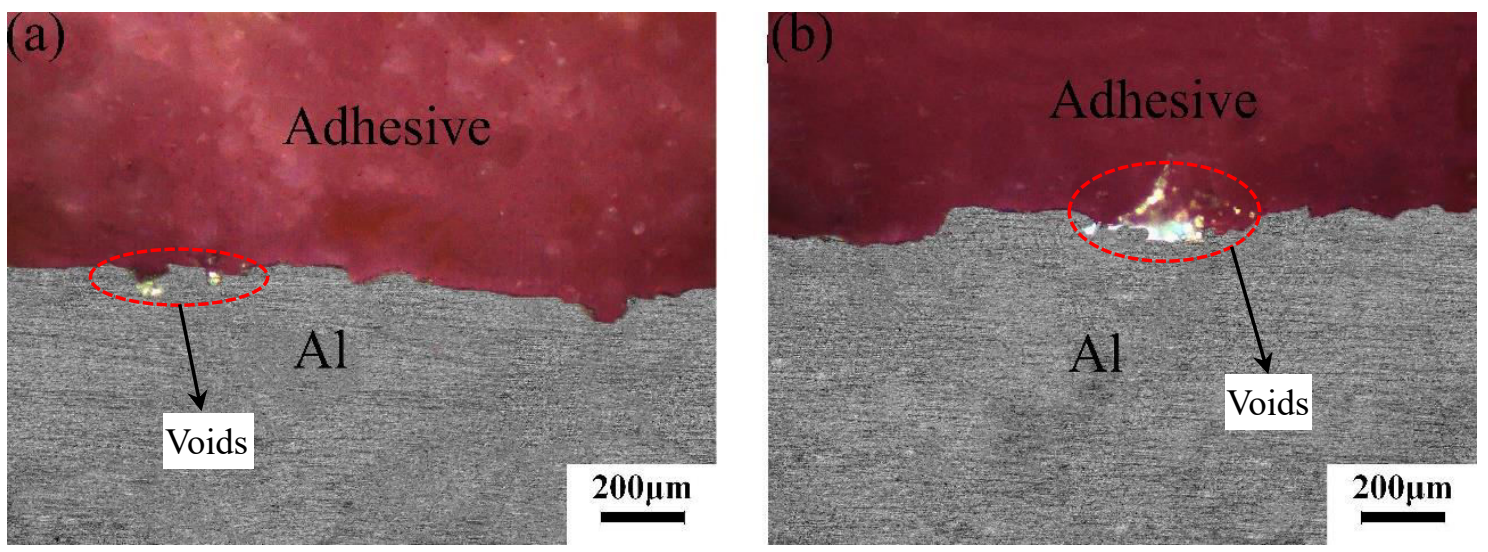

Fig. 14. OM images of the adhesively bonded joints cross-section with different surface treatment (a) grinded by P180, (b) grinded by P80 

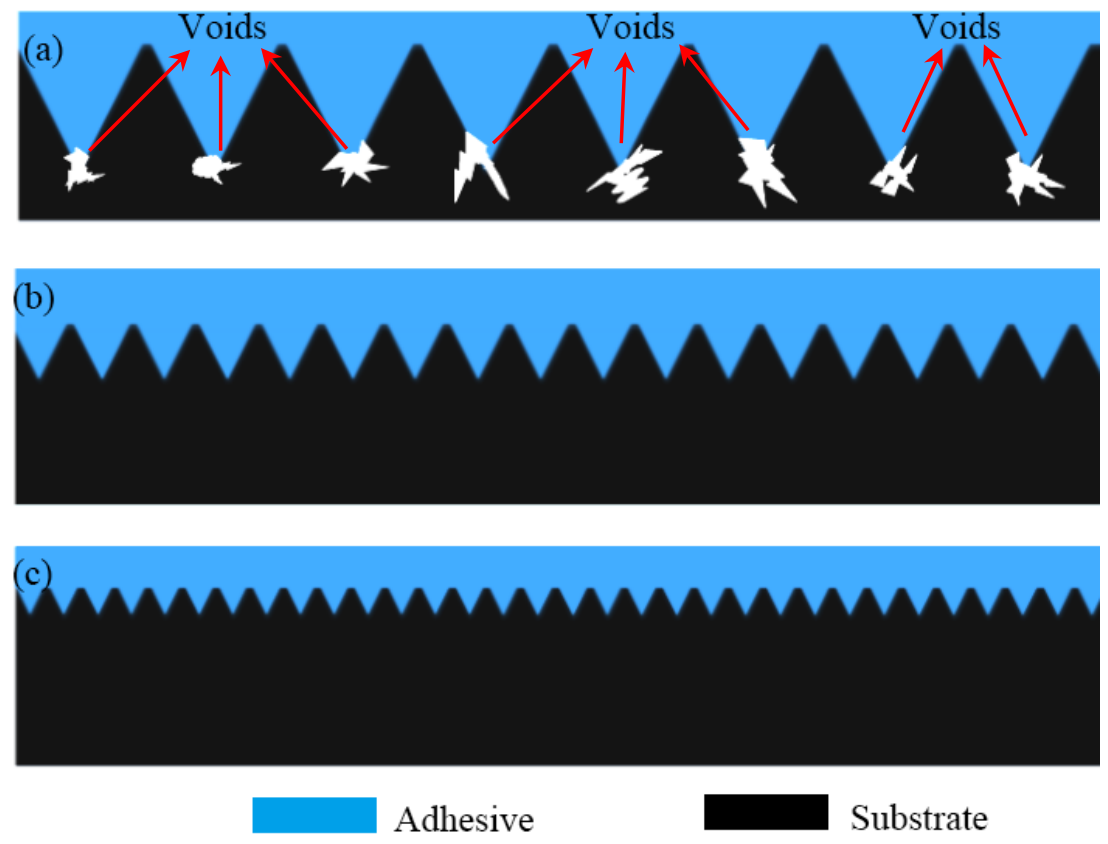

Fig. 15. The interface bonding diagram of different surface treatment prepared with (a) coarse; (b) moderate; (c) fine
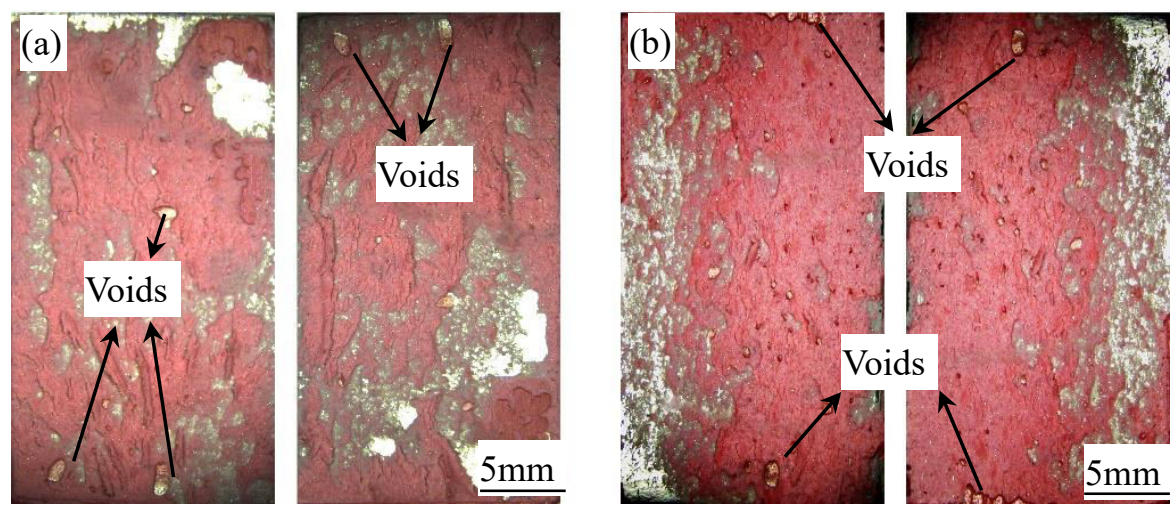

Fig. 16. Failure pattern (a) grinded by P180; (b) grinded by P80

It can be seen from Fig. 15 that the penetration of the epoxy on the grinded aluminum surface has two different modes. Fig. 15 (a) illustrates the distribution of the epoxy on the coarse substrate with surface roughness, for example the sheets grinded by P80 and P180, while Fig. 15 (b) and (c) depicts the distribution of epoxy on the sheet with moderate and fine roughness, representing the cross-section of adhesive joints made of sheets which were grinded by P320, P600 and P800 and un-grinded sheets 
1 surface, respectively. The capillary wettability mechanism of the grooves is applied to

2 explain the observed penetration process of epoxy [35]. The adhesive flows into the

3 grooves driven by the capillary force. The capillary wettability of the uneven surface

4 can be influenced by two key factors: the percentage of the groove depth to groove

5 diameter and the percentage of the groove diameter to the groove space. When the

6 percentages are at appreciate values, the substrates have the excellent wetting. Moreover,

7 the epoxy wetting mechanism changes with the different surface microstructure of

8 aluminum substrates. To verify the hypothesis, it is obvious to see that many voids in

9 the failure pattern of adhesively bonded joints after the shearing test as shown in Fig. 16.

10 It means that the adhesive is not entirely contacted with the aluminum sheets. The lap

11 shearing strength of adhesive joints with over roughening surfaces is very low because

12 of many internal voids and other defects in the joints.

\section{Conclusions}

In this research, the influence of surface roughness on the lap shearing strength and the failure behavior of the adhesively bonded aluminum joints were experimentally studied. The related mechanisms were systematically investigated. Main conclusions can be drawn as follows:

(1) The lap shearing strength of the adhesively bonded joints was obviously influenced by the surface roughness of the aluminum substrate. With the surface roughness of the aluminum substrate increased, the lap shearing strength of the joints initially increased and then decreased. When the surface roughness of the aluminum 
1 substrate reached to $6.08 \mu \mathrm{m}$ after roughening with sandpaper, a maximum lap shearing

2 strength of $30.4 \mathrm{MPa}$ was obtained for the joint, improved by $57.5 \%$ compared with that

3 of the joint made by sheets with surface roughness of $2.88 \mu \mathrm{m}$ without roughening.

4 Beyond that, the lap shearing strength decreases with the roughness of the substrates

5 decreasing.

6 (2) The mechanism for the change of the lap shearing strength with the surface

7 roughness is related to the modification of the mechanical interlocking effect, and the

8 microcosmic area, and wettability of the adhesive on the substrate. When the surface

9 roughness of the aluminum substrate ranged from $2.88 \mu \mathrm{m}$ to $6.08 \mu \mathrm{m}$, the lap shearing

strength of the adhesively bonded joints was mainly increased by increased

microcosmic surface area and improved mechanical interlocking. When it is in the range of $6.08 \mu \mathrm{m}$ to $13.74 \mu \mathrm{m}$, the strength of the joints was mainly affected by the wettability by which the surface energy is obviously decreased. Over roughening would worsen the wettability of the aluminum substrate which leads to a weakened lap shearing strength of joints.

(3) The failure behavior of the adhesively bonded aluminum joint was to a large extent by the surface roughened of aluminum sheets. The relation between the interfacial failure proportions to the surface roughness follows the same changing trend of the strength to the surface roughness, which also decreases firstly and then increases. Proper surface roughening can increase the micro surface area, which can reinforce the lap shearing strength. However, over roughening would induce voids, which turns the failure mode from the mixed mode of adhesion failure and interfacial failure to the 
1 single interfacial failure, by which the baring ability of the interface is largely

2 decreased.

3 Founding information This work was funded by the National Natural Science

4 Foundation of China [grant numbers 51975201, U20A20275], the Foundation of

5 Zhejiang Province Key Laboratory of Automobile Safety [grant number GL/20-002X]

6 and the Natural Science Foundation of Hunan Province, China [grant number

$7 \quad 2021 J J 40096]$.

8 Authors contributions

$9 \quad$ Jianpeng Liu: Investigation, Methodology, Writing-Original draft preparation;

$10 \quad$ Wei Wang and Yong Yan: Experiment preparation;

Zhigang Xue and Congchang $\mathrm{Xu}$ : Testing and data collecting;

12 Luoxing Li: Writing-Reviewing and Editing;

Hong He: Methodology; Revision; Writing-Reviewing and Editing.

\section{Compliance with ethical standards}

Ethical Approval: There was no ethical issue in this work.

Consent to Participate: There were no participants in this work.

Consent to Publish: The authors have consent to publish.

Competing Interests: None.

Availability of data and materials : Not applicable

\section{References}


[1] Wang S, Liang W, Duan L, Li G, Cui J (2019) Effects of loading rates on mechanical property and failure behavior of single-lap adhesive joints with carbon fiber reinforced plastics and aluminum alloys. Int $\mathrm{J}$ Adv Manuf Technol;106(5-6):2569-2581. https://doi.org/10.1007/s00170-019-04804-w

[2] Hamedi H, Kamyabi-Gol A (2021) A novel approach to modelling the bond characteristics between CFRP fabrics and steel plate joints under quasi-static tensile loads. Int J Adv Manuf Technol;116(9-10):3247-3261. https://doi.org/10.1007/s00170-021-07714-y

[3] Li J, Li Y, Huang M, Xiang Y, Liao Y (2018) Improvement of aluminum lithium alloy adhesion performance based on sandblasting techniques. Int J Adhes Adhes;84:307-316. https://doi.org/10.1016/j.ijadhadh.2018.04.007

[4] Cloquell AP, De Meter EC (2015) Experimental analysis of an adhesive surface grinding process. J Manuf Process;19:38-48. https://doi.org/10.1016/j.jmapro.2015.04.003

[5] Mandolfino C, Cassettari L, Pizzorni M, Saccaro S, Lertora E (2021) A design-ofexperiments approach to estimate the effect of plasma-treatment parameters on the mechanical resistance of adhesive-bonded joints. J Manuf Process;67:177-194. https://doi.org/10.1016/j.jmapro.2021.04.054

[6] Shahid M, Hashim AH (2002) Effect of surface roughness on the strength of cleavage joints. Int J Adhes Adhes;22(3):235-244. https://doi.org/10.1016/S0143-7496(01)00059-8

[7] Kunio Uehara, Sakurai M (2002) Bonding strength of adhesives and surface roughness of joined parts. J Mater Process Technol;127(2):178-181. https://doi.org/10.1016/S0924$\underline{0136(02) 00122-X}$ 
[8] Cho TM, Choo YS, Lee MJ, Oh HC, Lee BC, Park TH, et al. (2009) Effect of Surface

2 Roughness on the Adhesive Strength of the Heat-Resistant Adhesive RTV88. J Adhes Sci

\section{Technol;23(15):1875-1882. https://doi.org/10.1163/016942409x12508517390671}

[9] Budhe S, Ghumatkar A, Birajdar N, Banea MD (2015) Effect of surface roughness using different adherend materials on the adhesive bond strength. Appl Adhes Sci;3(1). https://doi.org/10.1186/s40563-015-0050-4

[10] Ghumatkar A, Sekhar R, Budhe S (2017) Experimental study on different adherend surface roughness on the adhesive bond strength. Mater Today: Proceedings;4(8):7801-7809. https://doi.org/10.1016/j.matpr.2017.07.115

[11] Şekercíoğlu T, Rende H, Gülsöz A, Meran C (2003) The effects of surface roughness on the strength of adhesively bonded cylindrical components. J Mater Process Technol;142(1):82-86. https://doi.org/10.1016/S0924-0136(03)00463-1

[12] Ghumatkar A, Budhe S, Sekhar R, Banea MD, Barros Sd (2016) Influence of Adherend Surface Roughness on the Adhesive Bond Strength. Lat Am J Solids Struct;13(13):2356-2370. https://doi.org/10.1590/1679-78253066

[13] Da Silva LFM, Ferreira NMAJ, Richter-Trummer V, Marques EAS (2010) Effect of grooves on the strength of adhesively bonded joints. Int J Adhes Adhes;30(8):735-743. https://doi.org/10.1016/j.ijadhadh.2010.07.005

[14] Wong RCP, Hoult AP, Kim JK, Yu TX (1997) Improvement of adhesive bonding in aluminium alloys using a laser surface texturing process. J Mater Process Technol;63(1-3):579584. https://doi.org/10.1016/S0924-0136(96)02687-8 
[15] Kwon D-J, Kim J-H, Kim Y-J, Kim J-J, Park S-M, Kwon I-J, et al. (2019)

Comparison of interfacial adhesion of hybrid materials of aluminum/carbon fiber reinforced epoxy composites with different surface roughness. Compos B Eng;170:11-18. https://doi.org/10.1016/j.compositesb.2019.04.022

[16] Van Dam JPB, Abrahami ST, Yilmaz A, Gonzalez-Garcia Y, Terryn H, Mol JMC (2020) Effect of surface roughness and chemistry on the adhesion and durability of a steelepoxy adhesive interface. Int J Adhes Adhes;96. https://doi.org/10.1016/j.ijadhadh.2019.102450 [17] Maressa P, Anodio L, Bernasconi A, Demir AG, Previtali B (2014) Effect of Surface Texture on the Adhesion Performance of Laser Treated Ti6Al4V Alloy. J Adhes;91(7):518-537. https://doi.org/10.1080/00218464.2014.933809

[18] Chen Y, Li M, Yang X, Luo W (2020) Damage and failure characteristics of CFRP/aluminum single lap joints designed for lightweight applications. Thin-Walled Struct;153. https://doi.org/10.1016/j.tws.2020.106802

[19] Asgharifar M, Kong F, Abramovitch J, Carlson B, Kovacevic R (2014) Wettability characterization and adhesion enhancement of arc-treated surface of aluminum alloys. Int $\mathrm{J}$ Adv Manuf Technol;71(5-8):1463-1481. https://doi.org/10.1007/s00170-013-5561-1

[20] Satheeshkumar V, Narayanan RG (2014) In-plane plane strain formability of adhesivebonded steel sheets: influence of adhesive properties. Int J Adv Manuf Technol;76(5-8):9931009. https://doi.org/10.1007/s00170-014-6335-0

[21] Guedes Pinto AM, Magalhães AG, Gomes da Silva F, Monteiro Baptista AP (2008) Shear strength of adhesively bonded polyolefins with minimal surface preparation. Int $\mathrm{J}$ Adhes Adhes;28(8):452-456. https://doi.org/10.1016/j.ijadhadh.2008.04.003 
[22] Boutar Y, Naïmi S, Mezlini S, Ali MBS (2016) Effect of surface treatment on the shear strength of aluminium adhesive single-lap joints for automotive applications. Int $\mathbf{J}$ Adhes Adhes;67:38-43. https://doi.org/10.1016/j.ijadhadh.2015.12.023

[23] Yang G, Yang T, Yuan W, Du Y (2019) The influence of surface treatment on the tensile properties of carbon fiber-reinforced epoxy composites-bonded joints. Compos B Eng;160:446-456. https://doi.org/10.1016/j.compositesb.2018.12.095

[24] Rudawska A, Danczak I, Müller M, Valasek P (2016) The effect of sandblasting on surface properties for adhesion. Int $\mathrm{J}$ Adhes Adhes;70:176-190. https://doi.org/10.1016/j.ijadhadh.2016.06.010

[25] Rudawska A, Jacniacka E (2009) Analysis for determining surface free energy uncertainty by the Owen-Wendt method. Int J Adhes Adhes;29(4):451-457. https://doi.org/10.1016/j.ijadhadh.2008.09.008

[26] Cui J, Wang S, Wang S, Chen S, Li G (2020) Strength and failure analysis of adhesive single-lap joints under shear loading: Effects of surface morphologies and overlap zone parameters. J Manuf Process;56:238-247. https://doi.org/10.1016/j.jmapro.2020.04.042

[27] Da Silva LFM, Carbas RJC, Critchlow GW, Figueiredo MAV, Brown K (2009) Effect of material, geometry, surface treatment and environment on the shear strength of single lap joints. Int J Adhes Adhes;29(6):621-632. https://doi.org/10.1016/j.ijadhadh.2009.02.012

[28] Boutar Y, Naïmi S, Mezlini S, da Silva LFM, Hamdaoui M, Ben Sik Ali M (2016) Effect of adhesive thickness and surface roughness on the shear strength of aluminium onecomponent polyurethane adhesive single-lap joints for automotive applications. J Adhes Sci Technol;30(17):1913-1929. https://doi.org/10.1080/01694243.2016.1170588 
[29] Wang X, Lin J, Min J, Wang P, Sun C (2018) Effect of atmospheric pressure plasma treatment on strength of adhesive-bonded aluminum AA5052. J Adhes;94(9):701-722. https://doi.org/10.1080/00218464.2017.1393747

[30] Packham DE (2011) Theories of Fundamental Adhesion. Berlin, Heidelberg: Springer (p):9-38. https://doi.org/10.1007/978-3-319-55411-2_2

[31] Yan Y, Chibowski E, Szczes A (2017) Surface properties of Ti-6A1-4V alloy part I: Surface roughness and apparent surface free energy. Mater Sci Eng C Mater Biol Appl;70(Pt 1):207-215. https://doi.org/10.1016/j.msec.2016.08.080

[32] Harris AF, Beevers A (1999) The effects of grit-blasting on surface properties for adhesion. Int J Adhes Adhes;19(6):445-452. https://doi.org/10.1016/S0143-7496(98)00061-X

[33] Hitchcock SJ, Carroll NT, Nicholas MG (1981) Some effects of substrate roughness on wettability. J Mater Sci;16(3 ):714-732. https://doi.org/10.1007/BF02402789

[34] Feng Z, Zhao H, Tan C, Chen B, Song X, Feng J (2020) Influence of laser process parameters on the characteristic of $30 \mathrm{CrMnSiA}$ steel substrate and adhesively bonded joints. Optics \& Laser Technol;123. https://doi.org/10.1016/j.optlastec.2019.105920

[35] Xu Y, Li H, Shen Y, Liu S, Wang W, Tao J (2016) Improvement of adhesion performance between aluminum alloy sheet and epoxy based on anodizing technique. Int $\mathrm{J}$ Adhes Adhes;70:74-80. https://doi.org/10.1016/j.ijadhadh.2016.05.007

[36] AJ K (1987) Adhesion and adhesives: science and technology. New York: Chapman and Hall. https://doi.org/10.1007/978-94-015-7764-9

[37] Bangash MK, Casalegno V, Kumar Das A, De la Pierre des Ambrois S, Ferraris M (2020) Surface machining of Ti6Al4V by means of Micro-Electrical Discharging to improve 
1 adhesive

joining.

$\mathrm{J}$

Mater

Process

Technol;286.

2

https://doi.org/10.1016/j.jmatprotec.2020.116813

3

[38] Feng Z, Zhao H, Tan C, Zhu B, Xia F, Wang Q, et al. (2019) Effect of laser texturing

4 on the surface characteristics and bonding property of $30 \mathrm{CrMnSiA}$ steel adhesive joints. $\mathrm{J}$

5 Manuf Process;47:219-228. https://doi.org/10.1016/j.jmapro.2019.09.046

6 